\title{
Uncertainty in WAG Injection Modelling using Empirical methods and Three-Phase Pore-Network Modeling with Rock Heterogeneity Effect
}

\author{
Ramyar Adnan Suramairy ${ }^{\# 1}$ and Ribwar Kermanj Abdulrahman ${ }^{\# 2}$ \\ ${ }^{1}$ Petroleum Engineering Department, Faculty of Engineering, Koya University, Kurdistan Region, Iraq \\ ${ }^{2}$ Chemical Engineering Department, Faculty of Engineering, Koya University, Kurdistan Region, Iraq
}

\begin{abstract}
The demand for fossil fuel for instance, oil and gas has been dramatic in recent decades. Therefore, many oil and gas companies are attempting to find out new technics for enhancing oil recovery for example, secondary and tertiary methods. Indeed, in recent years the interest in water alternating gas (WAG) has been increased as tertiary recovery method. Moreover, this method has been applied successfully in several fields around the world. In fact, the (WAG) injection method results in three-phase flow zones. Therefore, it is important to understand and well describing the multi-phase flow properties. This study investigated the uncertainty in multi-phase flow between pore-scale network modelling and empirical methods. Network models are being used as alternative for empirical methods to describe the multi-phase flow properties, since the former are physically-based tools which integrate the relevant pore-scale mechanisms while the latter often have little physical basis. The reservoir simulation has been employed to study the effect of rock heterogeneity on the absolute oil recovery obtained by empirical methods and pore network model during WAG injection in heterogeneous reservoirs. The results showed that rock heterogeneity could increase the three phase flow uncertainty between empirical methods and pore network modelling. Moreover; the investigation showed significant effect of rock heterogeneity (different relative permeability models) on overall WAG performance.
\end{abstract}

Keywords - Pore-scale, Water-alternating - Gas (WAG), Cluster. Breakthrough, Stone, Water cut, Eclipse.

\section{Introduction}

The demand for fossil fuel for instance, oil and gas has been dramatic in recent decades. Moreover, many oil reservoirs are depleting every day. Therefore, many oil and gas companies are attempting to find out new technics for enhancing oil recovery. In the recent years the interest toward wateralternating - gas (WAG) recovery has increased as one of oil recovery method techniques and it has been successfully applied in several oil fields especially in the Middle East [10]. Indeed, it has been estimated that more than half of the world unrecovered oil contained in the carbonate rocks in the Middle East. Therefore, (WAG) injection method may consider quite useful to be applied in Middle East reservoirs. In fact, WAG injection tends to improve the oil recovery by contacting the unwept zones, especially the attic or cellar oil by segregation of the gas to the top or the accumulation of the water to the bottom. Moreover, WAG injection could reduce the residual oil as a result, the injecting of two fluids (gas and water), and three-phase zones could be obtained lower remaining oil saturation. Furthermore, WAG injection will be improved the microscopic displacement [10]. The utilization of WAG injection must be accompanied with well description of the multi-phase flow. However, the real mechanism of the threephase flow that controls the process is remaining not well understood. Indeed, the measurement of the relative permeabilities has a particular challenge because there are an infinite number of different displacement paths. Therefore, it is impractical to measure relative permeabilities for all threephase displacement that take place in the reservoir [7]. As a result, empirical expression has been used to compute the relative permeabilities and capillary pressure for the threephase based on the available two-phase data $[5,7,21,31,32]$. However, those empirical models have no or little physical basis. Furthermore, an alternative approach has been utilized to develop physically-based three-phase network models that integrate all the relevant pore-scale mechanism and tuned to match the two-phase data in order to predict the relative permeablities and capillary pressure. This approach could improve the understanding of the three-phase flow and minimizing the uncertainty during gas injection projects.

In this paper we used sets of three-phase relative permeabilties and capillary pressure necessary obtained by empirical methods and network model for running the reservoir model [2]. Then we studied the uncertainty between the empirical methods (Stone's equations) and the network model during water alternating gas (WAG) injection in heterogeneous reservoirs. Also we studied the effect of different relative permeability models on overall WAG performance. The results show excellent matching between the simulated data and the experiments for water and gas phases. Whereas; during WAG injection there is a slight difference between the three-phase oil relative permeability measured from experiments and the one simulated by the networks. This could attributed to the new features included in the network which accurately detecting residual oil at its low saturations.. Furthermore; the investigation showed that different relative permeability models have a significant effect on increasing the recovery during WAG. This will help to expand the scope of understanding: why WAG is more interesting to be applied in heterogeneous reservoirs. 


\section{Three- phase flow measurement}

\subsection{Stone's Model I and II}

Empirical expressions have been adopted to estimate the relative permeability and capillary pressure for the three-phase based on the available two-phase data [5, 7, 21, 32, and 33]. Moreover, this model assumes that both gas and water relative permeabilities are functions of their own saturations. However, for oil relative permeability stone I proposed that 3-phase oil relative permeability is a function of a blocking degree for oil flow by water and gas that computed from two-phase data. However, stone II assumed the segregate flow condition. Therefore, no residual oil saturation is required to be defined [7]. However, those empirical methods are not more physically-based which fall to capture the oil flow at its low saturation and this indicates imprecise prediction of residual oil. Furthermore, they have been developed with an assumption of that the rocks are strongly water-wet [34].

\subsection{Pore-scale Network Model}

Network model is an alternative approach for the empirical methods to measure the three-phase properties (relative permeabilities and capillary pressure). The demand of constructing such models has been raised specially after the limitations that observed during applying the empirical approaches in multi-phase flow measurement. Traditionally, network models is a (two or three) dimensional model which representing the void space of the rock. The model composes of wide pores connected via narrower throats which assumed to be cylindrical or spherical shapes [8]. The study will use the network model that has already developed and validated [Øren, 2003] [23]. The realistic 3D pore-network extracted from the reconstructed pore space of Berea sandstone which will be used as inputs data to our model figure (1). The developed model as described in [2] will be used since it is a physically-based simulation tool. Moreover, multiple displacement implementation which allows the accurate modelling of the disconnected phase layers/clusters during high WAG floods [2, 35].

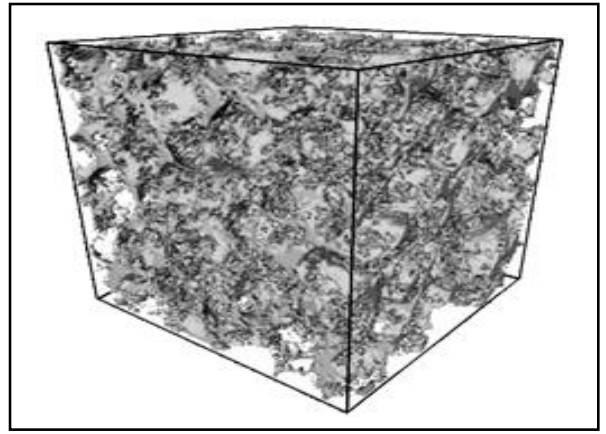

Figure.1-a Pore space reconstructed by process-based approach for Berea sandstone sample, taken from (Øren and Bakke 2003)

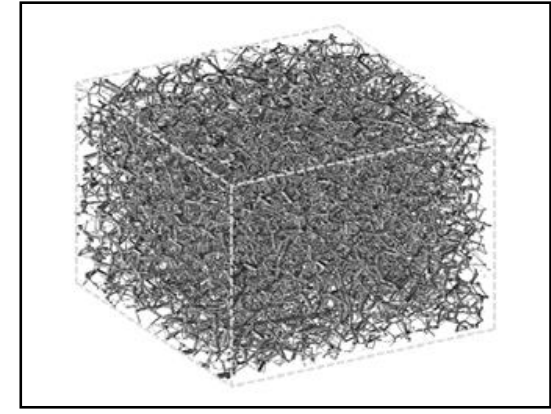

Figure.1-b Network extracted from process based reconstructed Berea sandstone sample

Figure.1 New network reconstructed from the network constructed from Berea sandstone.

This networks has been validated and described in details [23]. Moreover, the results from both experimentally and the predicted values from the network model that shows excellent agreement. Indeed, In the water-wet system the three-phase relative permeability of water and gas predicted by the network model and compared to the results determined experimentally in [22] and the conclusion of this is as follow, the gas relative permeability is a function of its own saturation (Figures 2), and for water, its relative permeability will be a function of its saturation (Figures 3). The predicted and the measured three-phase oil relative permeability is a function of both water and gas saturation and initial oil saturation (Figure 4) $[19,36]$.

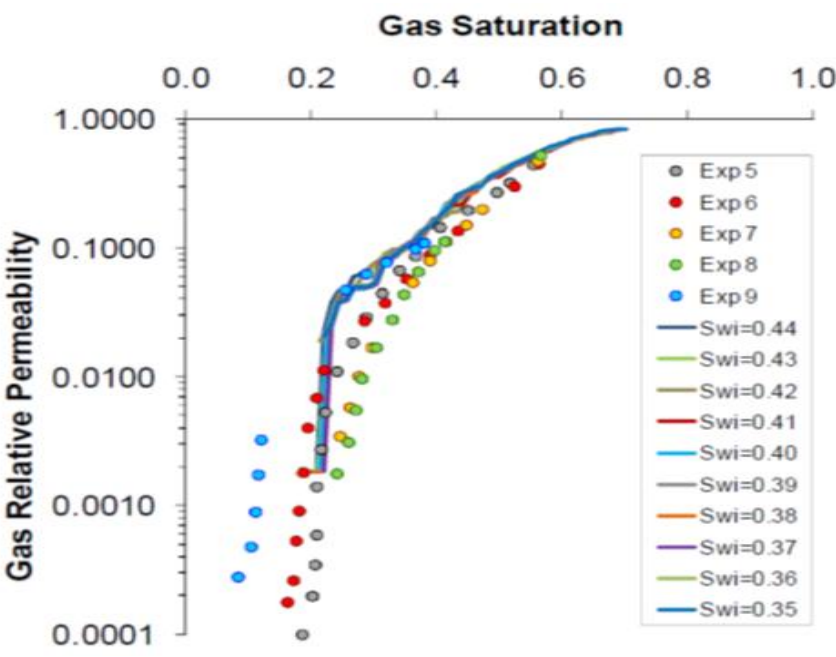

Figure.2 Comparison of gas relative permeability by network model with the experiment data for three-phase flow [2]. 


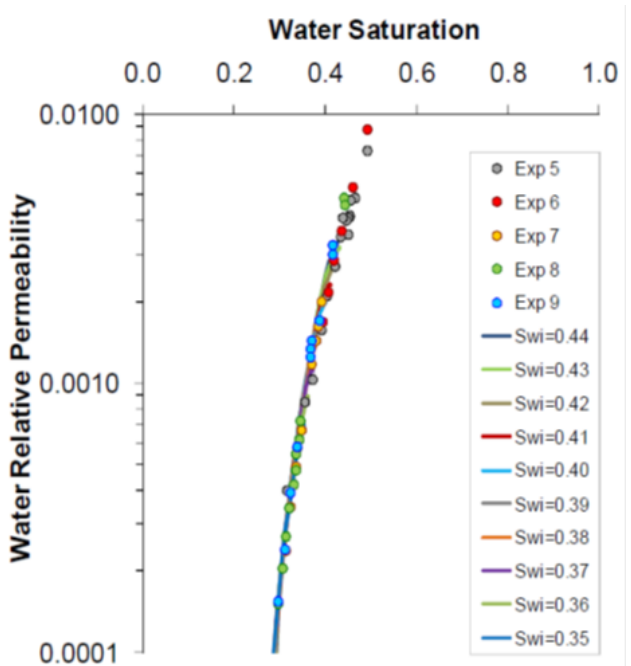

Figure. 3 Comparison of water relative permeability by network model with the experiment data for three-phase flow [2].

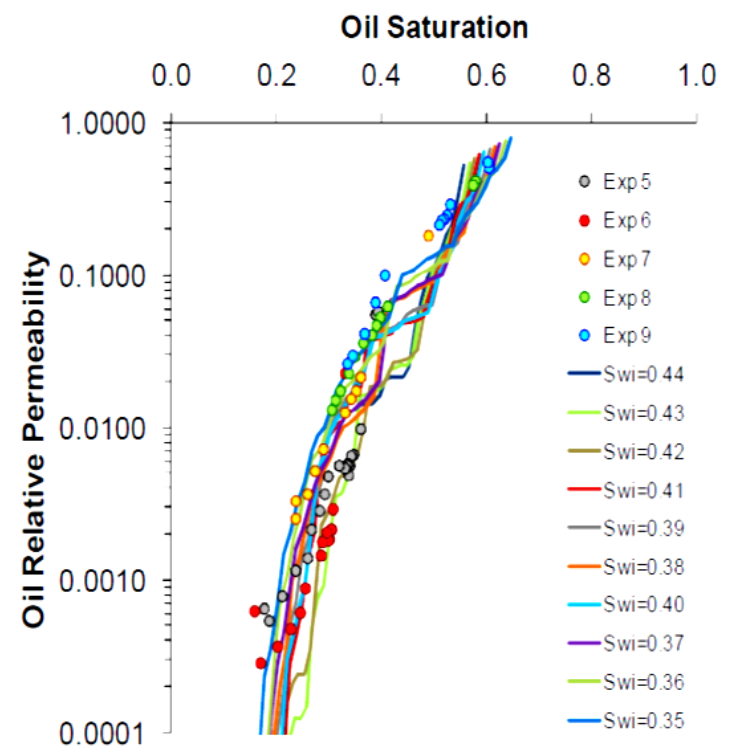

Figure.4 Comparison of oil relative permeability by network model with the experiment data for three-phase flow [2].

\section{RESERVOIR MODEL}

Brugge filed is a complete synthetic field which was built by (TNO) [10]. The geological structure of this field consists of stretched half-dome in the east/west direction with a fault of large boundary at the northern edge and an internal fault with $20^{\circ}$ angle of modest throw at the northern edge. The reservoir model used the truth case that consists approximately of $(75 \times 75 \times 2.5) \mathrm{m}$ grid block size with total active grid-blocks of
327,067 . This reservoir is under-saturated oil reservoir. Total 30 wells presented 20 producers and 10 injectors.

\section{Relative permeability curves}

Initializing the model required two-phase relative permeability curves. Figure (5) shows the two-phase system data being used for all the three methods (StoneI, StoneII and Network Model). Later the three-phase relative permeability has been obtained differently by each model based on these two phase data. Three network models have been used table (1). Three phase relative permeability obtained by network simulation have been used [35].

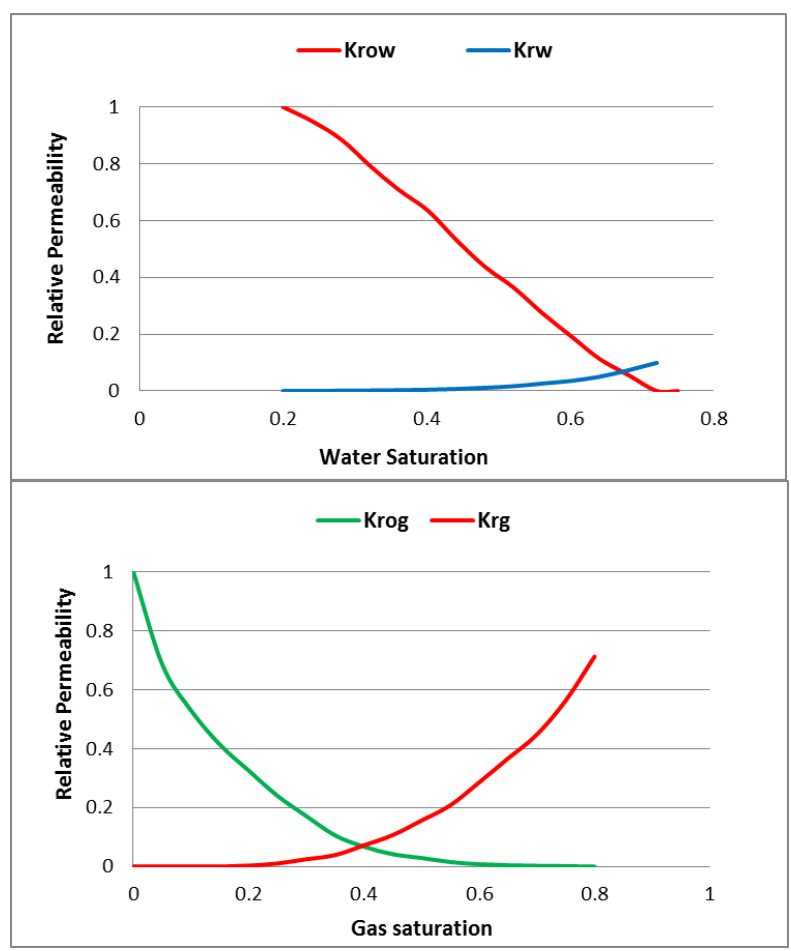

Figure 5. Two phase relative permeability curves

Table 1: pore networks parameters. 


\begin{tabular}{l|l|l|l}
\hline \multirow{2}{*}{ Parameters } & \multicolumn{3}{l}{ Networks } \\
\cline { 2 - 4 } & $\mathrm{A}$ & $\mathrm{B}$ & $\mathrm{C}$ \\
\hline $\begin{array}{l}\text { Number of } \\
\text { Nodes }\end{array}$ & 9315 & 12786 & 17657 \\
\hline $\begin{array}{l}\text { Number of } \\
\text { Bonds }\end{array}$ & 16590 & 21438 & 28404 \\
\hline $\begin{array}{l}\text { Permeability } \\
\mathrm{mD}\end{array}$ & 1390 & 472.678 & 29.6618 \\
\hline $\begin{array}{l}\text { Clay porosity } \\
\%\end{array}$ & 0.0014 & 0.006506 & 0.2598 \\
\hline $\begin{array}{l}\text { Net porosity } \\
\%\end{array}$ & 19.5281 & 16.5346 & 7.26506 \\
\hline $\begin{array}{l}\text { Total } \\
\text { porosity \% }\end{array}$ & 19.5295 & 16.5411 & 7.52488 \\
\hline $\begin{array}{l}\text { Formation } \\
\text { Factor }\end{array}$ & 28.9778 & 48.1238 & 329.337 \\
\hline \hline
\end{tabular}

\section{Results and discussion}

The reservoir-scale simulation has been run using the Eclipse simulator and the Brugge field reservoir model. The twophase relative permeability curves (Figure 5) used for all the three models runs. Firstly, only water injection started for all models. The recovery was identical for all the models because at this stage the flow has been controlled by two-phase system and the same oil-water relative permeability curve has been employed during all three cases (Figure 6).

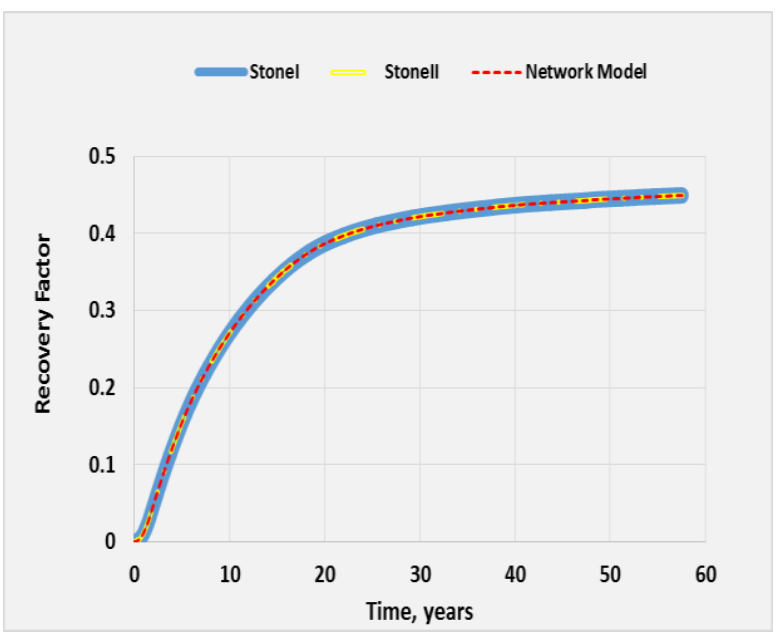

Figure 6. Oil recovery using water injection by StoneI, StoneII and Network Model

Figure 7 shows the oil recovery produced for the three models (StoneI, StoneII and Network Model) during WAG injection. When gas is injected into the reservoir, regions of two and three-phase develop in the reservoir. Each model uses different three-phase oil relative permeability, causing different sweeps of oil.

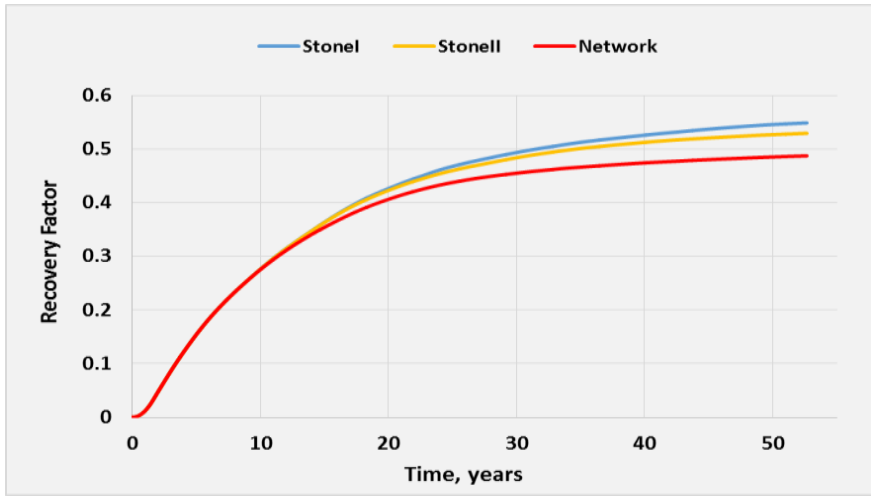

Figure 7. Oil recovery using WAG injection by StoneI, StoneII and Network Model for (Three Networks).

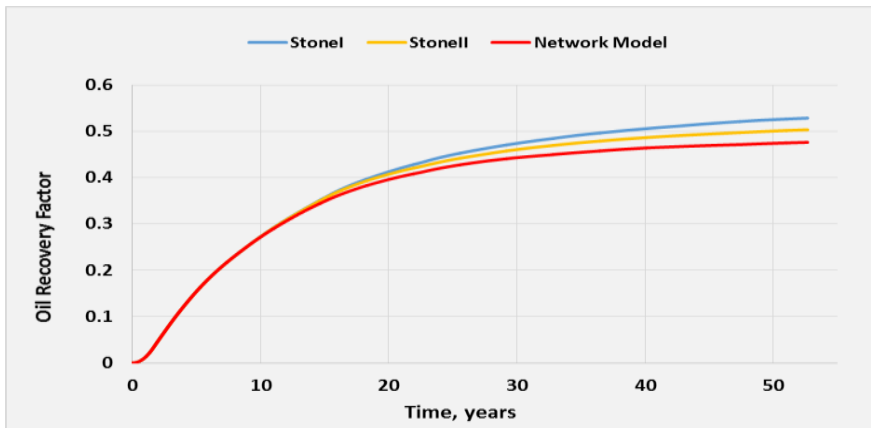

Figure 8. Oil recovery using WAG injection by StoneI, StoneII and Network Model for (One Network)

Initially, all three models produce the same recovery (Figure 7) until the gas breaks through (Figure 9); this occurs first in the Stone I model and gas is produced along with oil, resulting in a deviation of the oil recovery curve (Figure 7) compared to the other two runs using the different three-phase relative permeability models. During gas injection, gas moves to the top of the reservoir because it has lower density than oil and water. Based on the oil relative permeability surfaces (Figure 11), the oil has the same relative permeability for all models at the first water saturation paths. As the gas injected and the water saturation increase, the oil has the highest relative permeability for Stone I model, resulting in a fast sweep for the top layer of the reservoir model in the three-phase region and earlier gas breakthrough compared to the other two cases (Figure 9). As the gas progresses within the reservoir, the three-phase region expands and hence the three phase relative permeability increasingly dominates the flow of the reservoir fluids. 


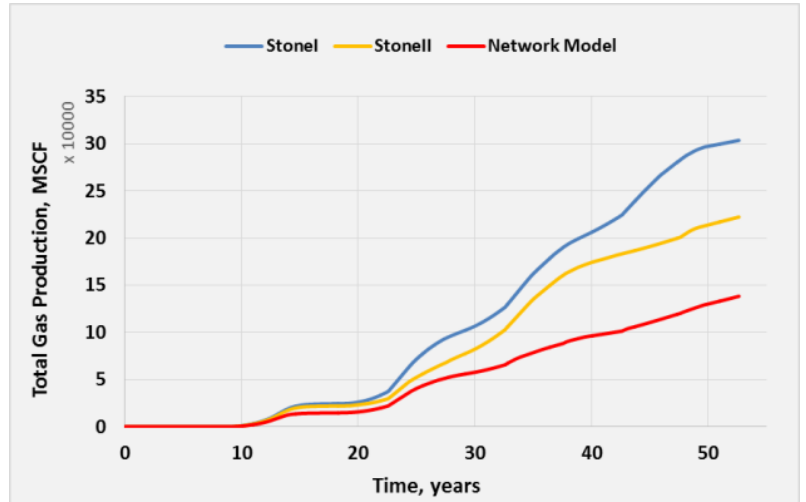

Figure 9. Total gad production by Stone I, Stone II and

Network Model during WAG injection for (Three Networks).

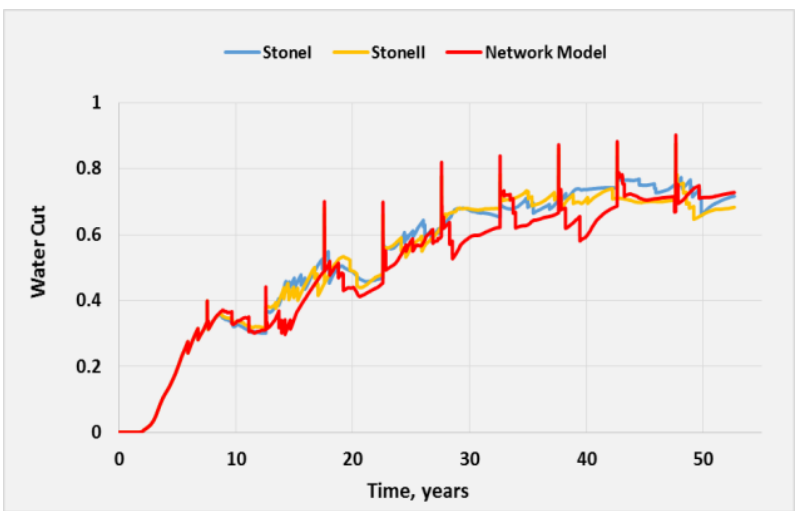

Figure 10. Water fraction cut by Stone I, Stone II and

Network Model during WAG injection for (Three Networks).
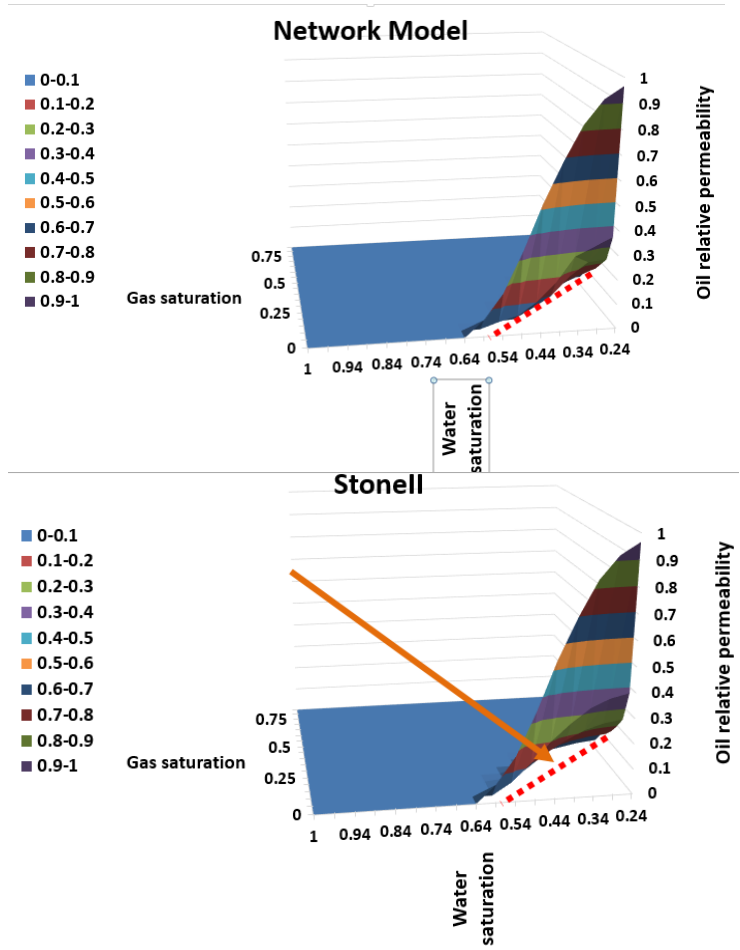

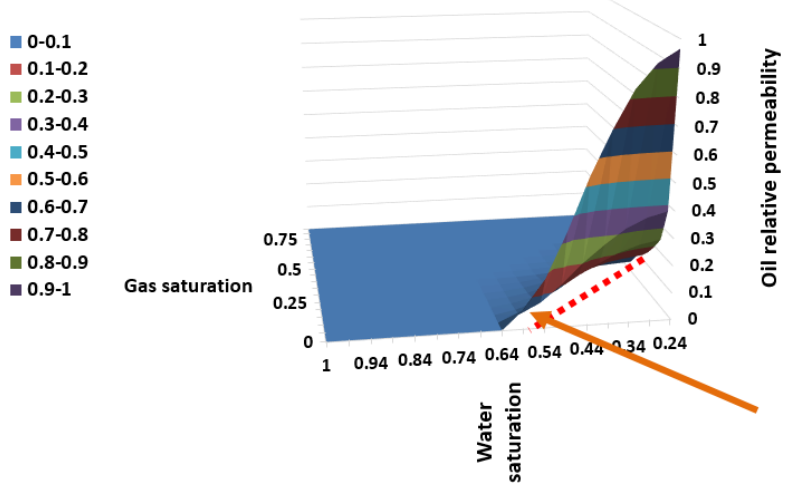

Figure 11. The three-phase oil relative permeability obtained by empirical models (StoneI and StoneII) and the network model for water-wet system.

The oil relative permeability of the network model is the lowest, leading to a low sweep efficiency of the oil, especially near the producer (figure 11). Despite, the gas production of the network is the lowest (figure 9) but the recovery of the network still has the lowest value. This could be attributed to the multiple displacements which employed in the network model being used here. As water saturation increase less oil will be displaced by gas. This gives an indication that less oil clusters connected to the outlets. The gas then starts to displace water as it connected to the outlet while the oil at this point trapped by water (figure 10). This leads to a decrease in the oil production. The oil recovery curve of the network model has the lower value comparing to StoneI and StoneII, resulting in the lowest total oil recovery. The difference between StoneI and StoneII curves and the network curve was about (6\% and 4\%) when three networks used (figure 7). This ratio has been decreased to $(5 \%$ and $2 \%)$ when one network has been used (figure 8). The oil recovery for the Stone II model continues to increase and recovery for Stone I and II models become more similar. However, the point at which StoneI and StoneII curves may overtake could be reached since the simulations have been stopped before that.

Furthermore; the effect of rock heterogeneity on WAG performance has been investigated by using different networks (Rock types) and the result showed increase in oil recovery when using different rock types (figure 12). Despite there was a slight increase in the recovery as more types used but this will help to expand the scope to understand: why WAG is more efficient when applied in heterogeneous reservoirs. 


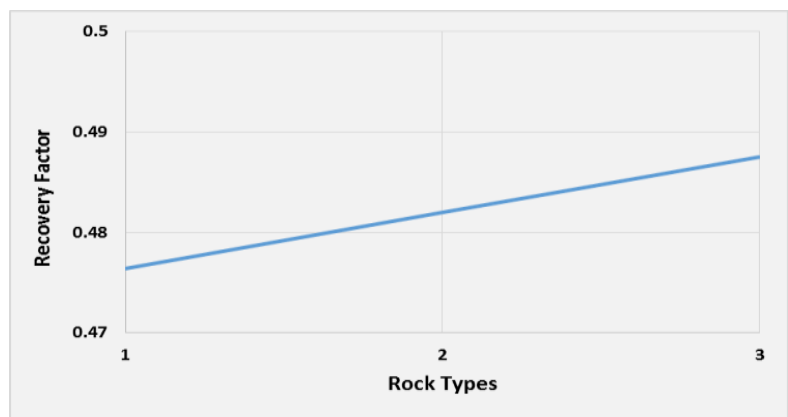

Figure 12. Oil recovery by WAG injection for different rock types.

\section{Conclusion}

The study is attempted to analyse the uncertainty between the empirical methods and the network model during field scale WAG injection by using sets of three phase relative permeability obtained from different models (stone I, stone II and network model) for water-wet system. The results showed variations in oil recovery curves for each model during the WAG injection. This could be attributed to that each model uses different three-phase oil relative permeability, causing different sweeps of oil. Network model has the lowest three phase oil relative permeability since this new model incorporates so-called multiple displacement. It has been observed during pore scale and field scale simulations that gas starts to displace water as its saturation increase whereas; at this point the oil trapped by the water and this will lead to lower recovery (figure 10). The difference in oil recovery between Stone I and network model was $(5 \%)$ and $(3 \%)$ for StoneII and the network model for one rock type. Rock type heterogeneity increased the difference between StoneI, StoneII and the network model to $(6 \%$ and $5 \%)$ respectively. Moreover; the rock type heterogeneity increasing the WAG efficiency by $2 \%$.

\section{References}

[1] Al-Dhahli, A., Geiger, S., and van Dijke, M. I. J. (2011). "Three-Phase Pore-Network Modelling for Mixed-Wet Carbonate Reservoirs." SPE Reservoir Characterisation and Simulation Conference and Exhibition, Society of Petroleum Engineers, Abu Dhabi, UAE.

[2] Al-Dhahli, A., Geiger, S., and van Dijke, M. I. J. (2012). "Accurate Modelling of Pore-scale Film and Layer Flow for Three-phase EOR in Carbonate Rocks with Arbitrary Wettability." SPE Improved Oil Recovery Symposium, Society of Petroleum Engineers, Tulsa, Oklahoma, USA.

[3] Al-Ghanim, W., R. Gharbi, and M.K. Algharaib, Designing a Simultaneous Water Alternating Gas Process for Optimizing Oil Recovery, in EUROPEC/EAGE Conference and Exhibition. 2009, Society of Petroleum Engineers: Amsterdam, The Netherlands.SPE 120375-MS.

[4] Andrews, J., M. Hettema, and T. Nesse, Injection Wells: A Case Study From the Statfjord Field, in SPE Annual Technical Conference and Exhibition. 2004: Houston, Texas.SPE 90949. [5] Baker, L .E. (1993). Three-Phase Relative Permeability of Water-Wet, Intermediate-Wet, and Oil-Wet Sandstone.
Seventh European Improved Oil Recovery Symposium, Moscow, Russia.

[6] Baojun, F., D. Xingjia, and Y. Cai, Pilot Test of Water Alternating Gas Injection in Heterogeneous Thick Reservoir of Positive Rhythm Sedimentation of Daqing Oil Field. SPE Advanced Technology Series, 1997. 5(1).[7] Blunt, M. J. (2000). An Empirical Model for Three-Phase Relative Permeability. Soc. Pet. Eng. J., 5 (4), 435-445.

[8] Blunt, M. J. (2001). "Flow in porous media - pore-network models and multiphase flow." Current Opinion in Colloid \&amp; Interface Science, 6(3), 197-207.

[9] Blunt, M. J., Jackson, M. D., Piri, M., and Valvatne, P. H. (2002). "Detailed physics, predictive capabilities and macroscopic consequences for pore-network models of multiphase flow." Advances in Water Resources, 25(8-12), 1069-1089.

[10] Christensen, J. R., Stenby, E. H., and Skauge, A. (2001). "Review of WAG Field Experience." SPE Reservoir Evaluation \& Engineering (04).

[12] Fatt I. The network model of porous media I. Capillary pressure characteristics. Trans AIME 1956;207:144_159.

[13] Fatt I. The network model of porous media II. Dynamic properties of a single size tube network. Trans AIME 1956;207:160_163.

[14] Fatt I. The network model of porous media III. Dynamic properties of networks with tube radius distribution. Trans AIME1956;207:164_181.

[15] Fenwick, D. H., and Blunt, M. J. (1998a). "Network Modeling of Three-Phase Flow in Porous Media." SPE Journal, 3(1), 86-96.

[16] Fenwick, D. H., and Blunt, M. J. (1998b). "Threedimensional modeling of three phase imbibition and drainage." Advances in Water Resources, 21(2), 121-143.

[17] Forrest, J.K., et al., Samarang Field - Seismic To Simulation Redevelopment Evaluation Brings New Life to an Old Oilfield, Offshore Sabah, Malaysia, in International Petroleum Technology Conference. 2009: Doha, Qatar.SPE 13162

[18] Gorell, S.B., Modeling the Effects of Trapping and Water Alternate Gas (WAG) Injection on Tertiary Miscible Displacements, in SPE Enhanced Oil Recovery Symposium. 1988: Tulsa, Oklahoma.SPE 17340

[19] Hui, M.-H., and Blunt, M. J. (2000a). "Pore-Scale Modeling of Three-Phase Flow and the Effects of Wettability." SPE/DOE Improved Oil Recovery Symposium, Copyright 2000, Society of Petroleum Engineers Inc., Tulsa, Oklahoma.

[20] Hui, M. H., and Blunt, M. J. (2000b). "Effects of wettability on three-phase flow in porous media." Journal of Physical Chemistry B, 104(16), 3833-3845.

[21] Juanes, R., \& Spiteri, E. (2004). Impact of Relative Permeability Hysteresis on WAG Injection. SPE 89921.

[22] Oak, M. J. (1990). "Three-Phase Relative Permeability of Water-Wet Berea." SPE/DOE Enhanced Oil Recovery Symposium, Tulsa, Oklahoma.

[23] Øren, P.-E., and Bakke, S. (2003). "Reconstruction of Berea sandstone and pore-scalemodelling of wettability 
International Journal of Engineering Trends and Technology (IJETT) - Volume 19 Number 1 - Jan 2015

effects." Journal of Petroleum Science and Engineering, 39(34), 177-199.

[24] Oren, P.-E., Bakke, S., and Arntzen, O. J. (1998). "Extending Predictive Capabilities to Network Models." SPE Journal, 3(4), 324-336.

[25] Øren, P. E., Billiotte, J., and Pinczewski, W. V. (1994).

"Pore-Scale Network Modelling of Waterflood Residual Oil Recovery by Immiscible Gas Flooding." SPE/DOE Improved Oil Recovery Symposium, 1994 Copyright 1994, Society of Petroleum Engineers, Inc., Tulsa, Oklahoma.

[26] Paterson, L., Lee, J.-Y., and Pinczewski, W. V. (1997). "Three-Phase Relative Permeability in Heterogeneous Formations." SPE Annual Technical Conference and Exhibition, 1997 Copyright 1997, Society of Petroleum Engineers, Inc., San Antonio, Texas.

[27] Pereira, G. G. (1999). "Numerical pore-scale modeling of three-phase fluid flow:Comparison between simulation and experiment." Physical Review E, 59(4), 4229-4242.

[28] Peters, L., Arts, R., Brouwer, G., Geel, C., Cullick, S., Lorentzen, R. J., Chen, Y., Dunlop, N., Vossepoel, F. C., Xu, R., Sarma, P., Alhuthali, A. H. H., and Reynolds, A. (2010). "Results of the Brugge Benchmark Study for Flooding Optimization and History Matching." SPE Reservoir Evaluation \& Engineering(3), pp. 391-405.

[29] Piri, M., and Blunt, M. J. (2005a). "Three-dimensional mixed-wet random pore-scale network modeling of two- and three-phase flow in porous media. I. Model description." Physical Review E, 71(2), 026301.

[30] Sohrabi (2000) 'Pore scale study of water alternating gas (WAG) injection using high-pressure micromodels with different conditions of wettability', SPE, (95594).

[31] Sohrabi (2001) 'Visualisation of Oil Recovery by Water Alternating Gas (WAG) Injection Using High Pressure Micromodels - Oil-Wet \& Mixed-Wet Systems', SPE, (71494MS), pp. 1429-1435.

[32] Stone, H. L. (1970). Probability Model for Estimation Three- Phase Relative Permeability. Journal of Petroleum Technology, 20, 214-218.

[33] Stone, H. L. (1973). Estimation of Three-Phase Relative Permeability and Residual Data, Journal of Canadian Petroleum Technology, 12, 53-61.

[34] Suicmez, V. S., Piri, M., and Blunt, M. J. (2006). "PoreScale Modeling of Three-Phase WAG Injection: Prediction of Relative Permeabilities and Trapping for Different Displacement Cycles." SPE/DOE Symposium on Improved Oil Recovery, Society of Petroleum Engineers, Tulsa, Oklahoma, USA.

[35] Ramyar Suramairy; Sebastian Geiger; Rink Van Dijke; Adnan Al-Dhahli. (2014). Field-Scale Simulation of WAG using Pore-Scale Network Modelling. American Journal of Oil and Chemical Technologies. 2 (3), 85-104.

[36] van Dijke, M. I. J., McDougall, S. R., and Sorbie, K. S. (2001). "Three-Phase Capillary Pressure and Relative Permeability Relationships in Mixed-Wet Systems." Transport in Porous Media, 44(1), 1-32.

[37] Van Dijke, M. I. J., M. Piri, J. O. Helland, K. S. Sorbie, M. J. Blunt, and S. M. Skjæveland (2007), Criteria for three-fluid configurations including layers in a pore with no uniform wettability, Water Resour. Res., 43, W12S05.

[38] Van Dijke, M. I. J. (2003) 'Pore-scale modeling of threephase flow in mixed-wet porous media: multiple displacement chains', Journal of Petroleum Science and Engineering,39(34), pp. 201-216. 